\title{
As ideologias de um grupo de professores-pesquisadores em tempo de isolamento
}

\section{social}

\author{
The ideologies of a group of teachers-researchers in time of social isolation \\ Las ideologías de un grupo de profesores-investigadores en tiempos de aislamiento social
}

Recebido: 22/02/2021 | Revisado: 28/02/2021 | Aceito: 05/03/2021 | Publicado: 11/03/2021

\author{
Marcia Borin da Cunha \\ ORCID: https://orcid.org/0000-0002-3953-5198 \\ Universidade Estadual do Oeste do Paraná, Brasil \\ E-mail: borin.unioeste@gmail.com \\ Saulo Cezar Seiffert Santos \\ ORCID: https://orcid.org/0000-0001-7890-1886 \\ Universidade Federal do Amazonas;Brasil \\ E-mail: sauloseiffert@ufam.edu.br \\ Diane Ferreira da Silva Dapieve \\ ORCID: https://orcid.org/0000-0003-2720-5180 \\ Universidade Estadual do Oeste do Paraná, Brasil \\ E-mail: dianeferreira.s@hotmail.com \\ Nathalie Akie Omachi \\ ORCID: https://orcid.org/0000-0002-7615-8432 \\ Universidade Estadual do Oeste do Paraná, Brasil \\ E-mail: akieomachi@gmail.com \\ Jéssica Engel do Nascimento \\ ORCID: https://orcid.org/0000-0001-5712-5646 \\ Universidade Estadual do Oeste do Paraná, Brasil \\ E-mail: jessicaenge193@hotmail.com \\ Olga Maria Schimidt Ritter \\ ORCID: https://orcid.org/0000-0003-4279-3232 \\ Universidade Estadual do Oeste do Paraná, Brasil \\ E-mail: olga.ritter@unioeste.br \\ Raquel Roberta Bertoldo \\ ORCID: https://orcid.org/0000-0001-5463-420X \\ Universidade Estadual do Oeste do Paraná, Brasil \\ E-mail: raquel.bertoldo@gmail.com
}

\begin{abstract}
Resumo
Este trabalho apresenta a análise de relatos de um grupo de professores-pesquisadores em tempo de isolamento social e o consequente repensar de suas práticas. Ressalta-se o lado sócio-histórico da linguagem, concebendo-se o enunciado enquanto produto da interação entre sujeitos socialmente organizados. Para tanto, apresentamos algumas ideologias e valores que se fizeram presentes em discursos (na forma de relato) de professores-pesquisadores que participam de um mesmo grupo de pesquisa. A metodologia empregada é qualitativa, do tipo estudo de caso. Os relatos foram obtidos por meio do preenchimento de um formulário online e analisados a partir dos pressupostos do Círculo de Bakhtin, considerando que o discurso não se reduz ao sistema linguístico, pois nele estão presentes nossas interpretações e visões de mundo e que se configuram com "ideologias". As análises dos relatos nos levaram à quatro ideologias: (1) peso da profissão, (2) valorização do professor e da ciência, (3) otimismo em relação ao momento vivenciado, oportunidade e aprendizagem durante o isolamento (lives) e (4) preocupação com o externo. Tais aspectos refletem um "tempo vivido" por este grupo de professores-pesquisadores, suas angústias e percepções de um momento histórico e único.
\end{abstract}

Palavras-chave: Análise discursiva; Valores; Pandemia; Ensino; Covid-19.

\begin{abstract}
This paper presents the analysis of reports of a group of professors-researchers in time of social isolation and the consequent rethinking of their practices. The socio-historical side of language is emphasized, conceiving the utterance as a product of interaction between socially organized subjects. To this do so, we present some ideologies and values that were present in discourses (in the form of a report) of professors-researchers who participate from the same research group. The methodology used is qualitative, of the case study type. The reports were obtained by filling out an online form and analyzed from the assumptions of the Bakhtin Circle, whereas discourse is not reduced to the linguistic system, because in it are present our interpretations and worldviews and that are configured with
\end{abstract}


"ideologies". The analyses of the reports led us to four ideologies: (1) burden of the profession, (2) valorization of the teacher and science, (3) optimism about the moment experienced, opportunity and learning during isolation (lives) and (4) concern with the external. These aspects reflect a "time lived" by this group of professors-researchers, their anguish and perceptions of a historical and unique moment.

Keywords: Discursive analysis; Values; Pandemic; Teaching; Covid-19.

\section{Resumen}

Este artículo presenta el análisis de los informes de un grupo de profesores-investigadores en tiempos de aislamiento social y el consiguiente replanteamiento de sus prácticas. Se resalta lavertiente sociohistórica del lenguaje, concibiendo el enunciado como producto de lainteracción entre sujetos socialmente organizados. Para eso, presentamos algunas ideologías y valores que estuvieron presentes en los discursos (en forma de informes) de profesores-investigadores que participan en un mismo grupo de investigación. La metodología utilizada es cualitativa, del tipo estudio de caso. Los informes se obtuvieron rellenando un formulario online y se analizaron a partir de los supuestos del Círculo de Bakhtin, considerando que el discurso no se reduce al sistema lingüístico, ya que contiene nuestras interpretaciones y visiones del mundo y que se configuran con "ideologías". El análisis de los informes nos llevó a cuatro ideologías: (1) peso de la profesión, (2) valoración del docente y la ciencia, (3) optimismo respecto al momento vivido, oportunidad y aprendizaje durante el aislamiento (vidas) y (4) preocupación con lo externo. Dichos aspectos reflejan un "tiempo vivido" por este grupo de docentes-investigadores, sus ansiedades y percepciones de un momento histórico único.

Palabras clave: Análisis Discursivo; Valores; Pandemia; Ensenãnza; Covid-19.

"As palavras são tecidas a partir de uma multidão de fios ideológicos e servem de trama a todas as relações sociais em todos os domínios".

Bakhtin

\section{Introduçãa}

Em momento tão controverso como o nosso, em meio a eventos simultâneos de pandemia de Covid-19, aulas remotas, debates/embates sobre Fake News, legitimação de resultados de pesquisa científicas e notícias do contexto político governamental, a profissão docente é atingida tanto no que se refere à sua prática, quanto àqueles docentes que desenvolvem pesquisas. As tensões acontecem em vários sentidos e, por vezes, inexplicáveis por conta da mudança na rotina e forma de trabalho, de um horizonte de expectativas no seu ofício e da sua experiência cotidiana mista (trabalho remoto e demandas do seu lar em isolamento social) e tantos outros.

Não há forma ideal de conhecer as mudanças e novos fenômenos da perspectiva da pesquisa educacional neste contexto. Sabemos que a articulação com o trabalho remoto, por meio do acesso à internet e suas plataformas de atividade, propicia a presença de discursos diversos, valores em choque, visões de mundo se encontrando (ou não!) e vozes repercutindo e refratando tudo isso.

Nesta complexa relação de contextos, vozes e mídias, se tem o discurso como uma das formas de conhecer e dialogar com o nosso tempo. Diante deste complexo mundo, buscamos neste artigo conhecer percepções e manifestações nos discursos de professores em formação de pesquisa e de pesquisadores, a fim de analisar algumas impressões das circunstâncias que estavam vivendo durante o tempo de isolamento social.

Nisto nos ancoramos em Bakhtin, pois é nele que podemos observar o movimento, a vida, o relativo e a abertura da construção do significado na comunicação, e isto pode ser percebido no dialogismo. Sabendo que o "[...] dialogismo são as relações de sentido que se estabelecem entre dois enunciados” (Fiorin, 2016, p. 22), ou seja, em diálogo, em palavra e sua contra palavra (resposta buscada). Todavia, reconhecemos que o estudo do discurso conta com outras tradições, como a francesa e a anglo-saxã. Mas, fazemos aqui um pequeno recorte na perspectiva russa do Círculo de Bakhtin, para interpretar e ver o contexto de trabalho docente de um grupo específico.

A partir da visão de discurso do Círculo de Bakhtin nos propomos a criar contextos de sentidos para professores que pesquisam e ministram aulas em instituições de educação formal e que pertencem ao Grupo de Estudos, Pesquisa e 
Investigação em Ensino de Ciências, GEPIEC/Unioeste. Entendendo que há uma mudança de práticas culturais, distanciamentos e aproximações com outras práticas culturais para promover a ação educativa e de pesquisa em um momento específico, isto é, a pandemia e o consequente isolamento social. Enquadramos os discursos desses participantes ao campo da educação e da pesquisa, falando de signos ideológicos próprios destas áreas e em choques de ideologias oficiais de suas instituições e de ideologias próprias do pensamento crítico da pesquisa, bem como da visão do seu lar, como pais, mães, filhos e filhas também.

Nesta perspectiva, procuramos analisar o que se revela no trabalho do professor-pesquisador em tempo de isolamento social, que ideologias estão presentes no discurso deste grupo, como enfrentam o "diferente" e diverso trabalho educacional. Aqui trazemos um recorte de uma realidade viva e em transformação, que se fez presente no ano de 2020.

\section{Marco Teórico}

Em Bakhtin, a comunicação é polifônica e "contaminada" por pensamentos distintos de esferas sociais diferentes. Todo discurso não é uma obra fechada, pertencente a um único indivíduo, mas é um processo heterogêneo, que se encontra na conjunção de outros discursos. Um signo ideológico é formado a partir da expressão cultural, dialogal, cuja referência é a palavra, os gestos, etc. e a significação acontece durante o ato da comunicação, em um determinado contexto social e histórico.

O signo ideológico, como elo contínuo da passagem entre a organização socioeconômica (infraestrutura) e os sistemas ideológicos (superestruturas), é a unidade possível material de pesquisa social (Bakhtin \& Volochinov, 1979). Esse signo é construído a princípio com pessoas de círculo próximo, como a família, sendo denominado de ideologia do cotidiano. Para Bakhtin "Um produto ideológico faz parte de uma realidade (natural ou social) como todo corpo físico, instrumento de produção ou produto de consumo; mas, ao contrário destes, ele também reflete e refrata uma outra realidade, que lhe exterior" (ibidem, p. 17). Diante disso, "Tudo que é ideológico possui um significado e remete a algo situado fora de si mesmo. [...] tudo que é ideológico é um signo. (ibidem, p. 17, grifo do autor).

Neste contexto, a palavra, na perspectiva do Círculo de Bakhtin, não é a palavra dicionarizada, é um fenômeno ideológico por excelência, sendo absorvida em função do signo. Ela (a palavra) não é apenas um signo puro, pois (ela) pode assumir vários sentidos e enfoques. Diante disso, o significado existe na relação entre o signo (palavra) e o sentido produzido em uma esfera social permeada por ideologias. Então, o sentido não está na frase ou no parágrafo, mas no enunciado como um todo. Para Miotello (2005, p. 170) “A representação do mundo é melhor expressa em palavras, pois que não precisa de outro meio para ser produzida a não ser o próprio ser humano em presença de outro ser humano."

O emprego efetivo da língua acontece por meio de enunciados (orais e escritos), concretos e únicos, proferidos pelos integrantes dessa ou daquela esfera da atividade humana. O enunciado é composto por seu conteúdo temático (ligado à atividade humana), estilo linguístico (expressão comunicativa) e construção composicional (forma de organização) (Bakhtin, 2016). O enunciado é definido também por três fatores: a) o horizonte espacial comum dos interlocutores; b) o conhecimento e a apreensão comum da situação por parte dos interlocutores; c) a avaliação comum dessa situação (Brait \& Melo, 2017).

Deste modo, a comunicação humana é carregada da ideologia do cotidiano e das esferas sociais, e a vida se expressa no diálogo via enunciado, que é dirigido à um interlocutor, e deste espera-se uma atitude responsiva (resposta real ou presumida. Assim, o dialogismo se torna ao alicerce da comunicação, sendo fonte mobilizadora dos signos ideológicos.

Segundo Miotello (2005), em Volshinov, no texto "Que é linguagem" de 1930, podemos encontrar a única definição de ideologia que pertence a alguém do Círculo: "Por ideologia entendemos todo o conjunto dos reflexos e das interpretações da realidade social e natural que tem lugar no cérebro do homem e se expressa por meio das palavras [...] ou outras formas sígnicas." (Voloshinov, 1998 apud Miotello, 2005, p. 169). Ainda para este autor, não cabe considerar a ideologia como falsa 
consciência, ou a expressão de uma ideia, mas deve ser considerada como uma tomada de posição determinada.

Além disso, é preciso considerar que, para o Círculo, existe a ideologia oficial e a ideologia do cotidiano. A primeira é entendida como dominante e procura implementar uma ideia única de mundo; a segunda é aquela que aflora dos encontros casuais e aleatórios, na proximidade social. Temos, de um lado a ideologia oficial, com sua estrutura relativamente estável, do outro, a ideologia do cotidiano, de estrutura instável e mutável. Contudo, ambas, a ideologia oficial e a ideologia do cotidiano formam o contexto ideológico completo, que tem existência recíproca, mantendo o foco na reprodução social. Deste modo é preciso compreender as duas ideologias em uma relação dialética e não de modo causal.

A título de exemplo podemos citar algumas ideologias do contexto pandêmico brasileiro, de um lado a ideologia oficial da Organização Mundial da Saúde - OMS, que recomenda o distanciamento social e o uso de máscara e, do outro, a ideologia do cotidiano observando um aumento de internações e mortes por conta do vírus SARS-cov2 ou, ainda, uma concepção de pandemia como um produto da mídia. Neste exemplo é preciso perceber que a ideologia se constrói entre ideias relativamente instáveis e ideias relativamente estáveis, as quais estão presentes na concepção de signo do Círculo. A linguagem é o lugar mais claro e completo da materialização do fenômeno ideológico (Ibidem, 2005).

Bakhtin (2016) entende que o discurso tem sentido quando contrapõe com a participação do outro, o discurso dialógico, que pressupõe polifonia (muitas vozes, planos de vozes), concentrado no relativo-dialógico discursivo (palavra e contra palavra, em movimento).

Segundo Bakhtin (2017), para uma interpretação criativa, aquela que é feita no "grande tempo", aquela não imediata ou para contextos recentes, é preciso observá-la de acordo com o desenvolvimento histórico da cultura, pois há um movimento constante de significação e ressignificação desta própria cultura. Para o empreendimento de uma interpretação é necessário o distanciamento. Essa é a alavanca mais poderosa para a interpretação. "A cultura do outro só se revela com plenitude e profundidade [...] aos olhos de outra cultura" (Bakhtin, 2017, p. 18 - 19).

Consideramos que o dialogismo é o modo de compreender o movimento da cultura de um determinado povo, sem o fechamento unilateral, mas diverso e complexo, no qual as lutas e disputas produz novos sentidos. Assentamos novas questões, as quais nossa cultura ainda não experienciou; procuramos respostas à essas questões, e a cultura do outro nos responde, mostrando novos aspectos, novas profundezas de sentido.

Tendo como base este olhar para o discurso é que empreendemos a análise apresentada neste artigo. Consideramos que é uma análise particular, de um grupo específico, mas que demonstra um pouco do muito vivido entre o mês de março e julho de 2020, momento no qual o Brasil encontrava-se no auge da pandemia do covid-19.

\section{Metodologia}

Esta pesquisa é qualitativa do tipo estudo de caso, que buscou analisar relatos escritos por um grupo de pesquisa na área de Ensino de Ciências. "Um caso é um acontecimento ou um fenômeno em estudo. O EC [estudo de caso] é uma metodologia de estudo de fenômenos individuais ou, processos sociais." (Pereira et al., 2018, p. 70). O grupo foco desta análise é o Grupo de Estudos, Pesquisa e Investigação em Ensino de Ciências - GEPIEC, que se encontra cadastrado no diretório de grupos do CNPq e na Pró-reitora de Pesquisa da Universidade Estadual do Oeste do Paraná - Unioeste. Fazem parte deste grupo docentes do Programa de Pós-graduação em Educação em Ciências e Educação Matemática (PPGECEM/Unioeste) e seus orientandos de mestrado, doutorado e pós-doutorado, docentes do curso de Química Licenciatura da Unioeste e docentes de universidades parceiras, bem como professores da rede estadual de educação básica e ex-alunos de iniciação científica, que já realizaram pesquisas no GEPIEC. Estes dois últimos (professores e ex-alunos) participam esporadicamente de alguma atividade e foram aqui incluídos porque receberam a solicitação de envio de relatos (material da 
nossa amostra).

Neste grupo de pesquisa e, em função do isolamento social, realizamos, a partir do mês de abril de 2020, reuniões remotas e, dentre outras atividades, foram constituídos fóruns de discussão sobre metodologias de análise qualitativa. Um dos fóruns passou a estudar mais detalhadamente a análise do discurso. A partir do estudo teórico das possibilidades de analisar um discurso e tendo no grupo alguns pesquisadores que já tinham conhecimento sobre as proposições do discurso a partir do Círculo de Bakhtin é que empreendemos nossa jornada de análise. Diante deste contexto a líder do grupo e coordenadora do fórum de análise do discurso solicitou aos membros do grupo de pesquisa um pequeno relato que pudesse servir de amostra para a realização de nossa análise. É, neste contexto que constituímos nosso corpus discursivo a ser analisado.

\subsection{0 corpus discursivo}

A análise do discurso de professores-pesquisadores ocorreu a partir de pequenos relatos escritos, os quais foram solicitados pela líder do grupo de pesquisa em uma situação de mensagem em grupo de WhatsApp. Nesta mensagem foi indicado um link que encaminhava para um formulário Google. Neste formulário era possível escrever de cinco a dez linhas as percepções sobre o trabalho do professor-pesquisador em tempo de isolamento social. Denominamos professor-pesquisador os membros do grupo que, de modo geral, atuam tanto na docência quanto na pesquisa. O uso de hífen (-) pretende dar a ideia de duas tarefas (pesquisar e ensinar) que ocorrem de forma vinculada, uma em relação a outra. Ao responder a solicitação, o respondente deixou seu relato utilizando pseudônimos, de modo que não fosse possível sua identificação. O conteúdo da mensagem teve a seguinte redação:

\section{Boa noite pessoal}

O fórum de análise do discurso necessita da colaboração de vocês escrevendo um pequeno relato sobre "Eu e a pandemia: professor-pesquisador em tempo de isolamento social". Os relatos (cinco a dez linhas) servirão de material de análise do grupo. A escrita deve ser feita no formulário a seguir e com uso de pseudônimo. (link do questionário). Eu enviei a alguns no e-mail, mas como não tenho todos os e-mails deixo o link aqui. Contamos com a colaboração de todos, depois apresentaremos nossas análises ao grupo.

Os participantes do fórum de análise do discurso também devem escrever. Mesmo quem não está participando das discussões nos fóruns pode contribuir escrevendo seu relato.

Mensagem e link enviado por WhatsApp no dia 14 de julho de 2020, às 20 horas e cinco minutos.

Dentre os 27 membros do grupo de pesquisa e que receberam a solicitação, obtivemos um total de 17 relatos, que constituiu o nosso corpus de análise.

\subsection{Percurso de análise}

Os relatos foram organizados em ordem alfabética, a partir dos pseudônimos, que os próprios autores indicaram. Feita a organização alfabética, numeramos linha a linha, o que resultou em 188 linhas para a análise. Antes de cada relato estava indicado o pseudônimo do autor, de modo que o analista pudesse reconhecer o início e o término de cada depoimento.

A partir da organização inicial, os relatos foram enviados aos analistas (membros do fórum) via correio eletrônico, com a indicação de que a ordem e a numeração não deveriam ser alteradas, pois as análises seriam realizadas por diferentes pesquisadores, em momentos individuais e coletivos. Para condução do processo de análise sistemática elencamos três fases, a saber: 1. Observar a variabilidade, as diferenças entre as narrações (atividade individual); 2. Criar um esquema analítico inicial, que poderia ser alterado durante o processo de análise (em grupo); 3. Praticar a análise por meio da discussão em grupos.

Inicialmente, os analistas deveriam olhar para os relatos observando o dito e os silêncios (o não dito). Neste contexto é necessário ter consciência aprimorada das tendências e contextos sociais, políticos e culturais. É importante também produzir leituras e releituras dos relatos, observando os detalhes e fazendo anotações. 
Como questão orientadora para análise, ou seja, nossa interrogação de pesquisa temos: O que se revela no trabalho do professor-pesquisador em tempo de isolamento social? Além desta questão central, outras foram sugeridas aos analistas, de modo que o "olhar" de todos tivessem o mesmo foco (ou algo aproximado). São elas: Que tipo de explicações os relatos dão para o trabalho em tempo de pandemia?; Que sentimentos aparecem quando falam do assunto?; Que soluções têm sido dada para enfrentar o problema?

A partir da primeira fase de análise, criamos coletivamente um esquema analítico prévio. Este esquema contém todos os pontos elencados por aqueles que estavam participando do fórum de análise do discurso. Assim, o esquema analítico ficou estruturado com quatro grandes eixos:

1. Sentimentos contraditórios (medo, aflição, angústia, ansiedade, esperança, reflexão, mudança, afetar-se pelo externo, inércia, fuga, crise emocional);

2. Dificuldades enfrentadas: incerteza, o novo, o peso da profissão, busca de superação;

3. Mudança: oportunidade e aprendizagem durante o isolamento (lives), nova rotina, reconstrução pessoal, desafios, adaptação;

4. Esperança/fragilidade: valorização do professor, valorização da ciência, visão positivista da ciência, visão romântica da profissão.

Tendo como base os questionamentos e o esquema analítico, o grupo passou à fase das análises, orientado pelo pressuposto teórico e considerações sobre o discurso do Círculo de Bakhtin e as possibilidades de olhar o discurso como forma de constituição de ideologias que perpassam nossos contextos sociais e, as quais, estão associados determinados valores.

Nesta análise consideramos que na perspectiva do Círculo de Bakhtin, a linguagem deve ser entendida como o lugar do código-ideológico, do signo ideológico por excelência, sendo impossível descolá-la do meio social e do contexto social imediato de sua constituição. (Bakhtin \& Volochinov, 1979). Diante desta perspectiva e, diferentemente da visão de língua como um sistema abstrato de formas, consideramos a linguagem como um fenômeno social da interação verbal, realizada por meio da enunciação ou das enunciações.

Entendemos, assim como Brait (2006), que o tributo essencial dado pelo Círculo de Bakhtin é uma teoria fundamentada em uma postura dialógica diante do corpus discursivo, da metodologia e do pesquisador. Podemos encontrar no Círculo de Bakhtin um sujeito consciente de suas escolhas, no momento em que ele produz enunciados, pois em cada enunciado

[...] sentimos a intenção discursiva de discurso ou a vontade discursiva do falante, que determina o todo do enunciado, o seu volume e suas fronteiras. Imaginamos o que o falante quer dizer, e com essa ideia verbalizada (como a entendemos) é que medimos a conclusibilidade do enunciado (Bakhtin, 2003, p. 281, grifo do autor).

\section{Resultados e Discussão}

As análises dos relatos nos levaram a quatro ideologias: (1) peso da profissão, (2) valorização do professor e da ciência, (3) otimismo em relação ao momento vivenciado, oportunidade e aprendizagem durante o isolamento (lives) e (4) preocupação com o externo. A cada ideologia estão associados os valores, que são representados pelas percepções do coletivo, considerando todo contexto da produção dos enunciados expressos pelo gênero "relato pessoal".

Considerando que, o gênero discursivo do relato pessoal comporta a interpenetração das atividades de várias esferas institucionais como instituição de ensino que trabalha, instituição de pesquisa que participa, instituição familiar em que habita e realiza atividades remotas diversas e relações informais da vida cotidiana. Desta forma, as ideologias constituídas nos relatos não são produtos puros de uma esfera específica, mas híbrido, por não dizer uma penumbra entre várias atividades e locais, as quais se encontram neste contexto em interação, dialogismo e polifonia. 
Apresentamos as ideologias e os valores reportando-se à extratos obtidos a partir dos relatos. A indicação "L" significa a linha (ou linhas) em que o enunciado se encontra no corpus de análise, constituído a partir da sequência de relatos e numeração linha a linha.

Na sequência está a análise do discurso, indicando inicialmente a referência à ideologia observada nos relatos, seguida da sua explanação e valores encontrados, finalizando cada uma delas com extratos dos relatos, que orientam o leitor para a observação de fragmentos em que tais ideologias estão mais afloradas e perceptíveis. Salientamos que a análise do discurso se dá no interior do enunciado, assim os extratos refratam um pouco daquilo que se encontra presente nos enunciados completos, ou seja, em nossos relatos.

\subsection{Peso da profissão}

Com surgimento da pandemia os professores e pesquisadores precisaram adaptar-se as novas tecnologias e rotina de trabalho, que foram modificadas devido ao contexto pandêmico. A sala de aula e laboratório foram adaptados para o home office, de forma que, o ambiente de descanso e trabalho foram confundidos. Também podemos considerar que alguns professores assumiram as aulas virtuais/remotas sem o devido preparo, enquanto outros tiveram um tempo de adaptação. Em decorrência do novo, os professores ficaram sobrecarregados entre formação continuada, aulas, atendimento aos pais e estudantes e produção de material didático. Já os pesquisadores, modificaram seus projetos de pesquisa e extensão, fazendo adaptações para o ambiente virtual.

Valores em comum: Imposição de uma nova adaptação, formação (lives), rotina de trabalho modificada, sentimento de cansaço pela sobrecarga de trabalho e pelo enfrentamento de novos desafios. A tecnologia como aliada do trabalho docente, mas também exigindo conhecimento diferenciado para seu uso em atividades didáticas.

Nesse cenário, o conjunto de valores que a carreira, enquanto docente/pesquisador, fizeram com que o professor tivesse que se adaptar sob vários aspectos, enfrentando diferentes desafios diários e meio à uma rotina familiar que foi alterada, seja pelo trabalho remoto, seja em atender aos seus familiares. Nos extratos de relatos a seguir podemos observar as marcas discursivas decorrentes desta ideologia. Nestes há sentimentos que expressam o peso da profissão em decorrência da mudança repentina, dentre outros aspectos, como cansaço e os desafios.

Ada Lovelace: Mas não foilé fácil se manter ativo e encontrar uma nova rotina de trabalho, principalmente quando se pensa em ensinar com tanta distância [...] senti que a missão de ser professor se tornou mais pesada e cansativa". (L. 3 - 4 e 7$)$.

Ana: [...] fomos obrigados a compreender o funcionamento e saber utilizar diferentes tecnologias para conseguir desenvolver nossas atividades de pesquisa, capacitação profissional e ensino e aprendizagem (L. 13 - 15).

Bem louca: [...] momento muito desafiador, principalmente no sentido da adaptação ao "novo" de maneira tão repentina e imediata, sem que tenha havido tempo suficiente para reflexões, foram postas, no sentido de "cumpra-se de imediato. (L. 35 - 37).

Jasmin: Neste período de isolamento social, um dos meus primeiros pensamentos "foi e agora como serei professor sem sala de aula, sem lousa e sem contato visual?" Tarefa difícil, visto que eu não acredito em ensino a distância. Como pesquisar se não poderei coletar dados de modo presencial, como tinha planejado? (L. 95 - 98).

Nina: Na atuação docente, os desafios são inúmeros e diários, a carga horária aumentou significativamente, pois, exige que estejamos atentas a todas as modificações e orientações, bem como, no atendimento online das famílias e alunos (L. 160 - 162).

Violeta: Os desafios enfrentados durante a pandemia não são poucos, principalmente quando se busca equilibrar as atividades profissionais e pessoais [...] Como professora/pesquisadora foi necessário aprender novas formas de realizar as diferentes tarefas profissionais, o que não tem sido fácil. (L. 178 - 179 e 185 - 186).

\subsection{Valorização do professor e da ciência}

A ideologia forma-se no contexto social-histórico e, no qual, tem-se presenciado uma grande desvalorização do professor/pesquisador nos últimos anos. Isto tem sido agravado com a mudança do cenário político (ideologia oficial), em que 
a educação e pesquisa vêm sofrendo cortes com maior intensidade a partir de 2018. A ciência é posta em conflito com o senso comum, surgindo teorias contra as pesquisas científicas. O professor é visto como formador de ideologias, de modo particular, ideologias partidárias. A posteriori, a mudança do cenário nacional devido à pandemia, no qual o Brasil enfrentou a mudança em diferentes aspectos. $\mathrm{O}$ ambiente escolar modificou-se, passando ocorrer na casa dos estudantes, com maior autonomia. A esperança de que a carreira docente e a pesquisa serão valorizadas está presente nos relatos.

Valores em comum: Preocupação com aprendizagem do aluno em primeiro lugar, importância do professor na sociedade, visão positivista da ciência. Em alguns relatos é possível encontrar uma visão romantizada da profissão docente, na qual o professor se preocupa mais com o estudante do que com ele. Mas há, sobretudo, uma percepção de que a profissão docente será valorizada pós pandemia.

Bem Louca: [...] identifico como um momento único e oportuno para grandes e importantes reflexões que de fato podem, em uma perspectiva otimista, levar a significativas mudanças, principalmente no que se refere ao importante papel desenvolvido pelo professor no processo de ensino e aprendizagem [...] (L. 39- 42).

Esperança: [...] como ser professor, é uma luta diária por reconhecimento e valorização. Espero que essa pandemia mostre a sociedade como um todo a importância do professor na vida de indivíduo (L. 72 - 74).

Joana Maria: Contudo, acredito ser o momento para mostrarmos a nossa importância social, de pesquisadores, professores, aqueles que muitas vezes pensam primeiro no bem estar dos outros para depois em si mesmo (L. 111 113).

Ainda nos relatos é possível identificar uma visão positivista da ciência, na qual é ciência pode ser a única capaz de "salvar" a população dos males da pandemia.

Joana Maria: A Ciência vinha e ainda vem passando por um grave desinteresse dos poderes públicos, porém é por meio dela que se pode encontrar uma solução para a pandemia, mas mesmo assim os cientistas/pesquisadores continuam sendo julgados. (L. 108 - 110).

Luana: [...] enquanto estudante da área de ensino de Ciências percebo a importância do ensino e da pesquisa nas escolas e universidades principalmente em situações como estas, nas quais somente a ciência pode encontrar saídas e alternativas. (L. 132 - 134).

\subsection{Otimismo em relação ao momento vivenciado}

É interessante ressaltar a resiliência que o "ser humano" é capaz de possuir diante dos desafios e dificuldades que abalam as estruturas até então "bem" estabelecidas, como rotina de trabalho, a família, hobbys, entre outros. A pandemia teve seu início em outros países no final de 2019 e no Brasil em março de 2020. Tanto no Brasil como no exterior, todas as pessoas passaram por períodos de isolamento e sem previsão de término, mas depois de algum tempo, todos percebem a necessidade de recomeçar, de adaptar-se a um "novo mundo", não mais aquele que conhecíamos. Neste contexto alteramos a interação com amigos, familiares e vamos vivendo nossas vidas, moldando-nos conforme é preciso e ressignificando os meios tecnológicos, de modo, a aproximar os que estão distantes, dar continuidade a pesquisa, fortalecendo o trabalho remoto, repensando o ensino que era bem estruturado e agora a necessidade de readaptar, entre outros.

Nesse sentido, há marcas nos fragmentos de leveza e otimismo (dentro de sua realidade), em que nos relatos se apresentam, além dos obstáculos que surgiram no contexto pandêmico, em meio ao caos e de um turbilhão de mudanças aparecem outras oportunidades de estudo, aprendizagem, reflexão e autoconhecimento.

Valores em comum: autoconhecimento, reflexão, oportunidade de aprendizagem e continuação da pesquisa, mudanças pessoais e profissionais.

Ana: [...] reconstruir, repensar as ações de interferência no meio ambiente, nos aproximarmos das tecnologias e percebermos as possibilidades significativas de trabalho que essas nos oferecem. (L. 17, 18 e 19).

Henrique: Uma vantagem que tenho observado, e aproveitado na medida do possível, é a participação em atividades remotas com profissionais de variadas áreas, o que para mim representa uma importante forma de formação 
continuada. (L. 82 - 85).

Isabel: [...] vem contribuindo para momentos significativos para o desenvolvimento da minha pesquisa, estudos, e também está permitindo repensar sobre o universo virtual, pois tenho utilizado ferramentas virtuais para assistir lives de pesquisadores no ensino de ciências (L. 88 - 90).

João Batista: Acredito que há uma oportunidade de pensar em possibilidade de uso racional e criativo dessas ferramentas para a coleta e análise de pesquisa para este contexto com maior capilaridade. (L. 123 -125).

Maria: Acredito que, esse novo cenário tem gerado aprendizagem significante para os professores que estão tendo que se reinventar e adaptar sua metodologia de ensino ao contexto atual, e também criar novos laços com os estudantes. (L. 153 - 155).

Propesq: [...] me sinto constantemente desafiada a pensar e repensar novas formas de fazer, da melhor maneira possível, as atividades (ensino, pesquisa e extensão), com os recursos que tenho disponíveis. (L. 171 - 173).

Anne: Participei de inúmeras reuniões remotas, lives, etc., isso tem sido muito bom, pois as lives são sobre temas muito interessantes, de boa qualidade e possibilitam uma interação (mesmo que distante) com outras pessoas. (L. 24 - 27).

\subsection{Preocupação com o externo}

A população passa atribuir uma interpretação indutivista da ciência, surgindo teorias de terraplanismo, vacina como difusor de doenças, universidade enquanto espaço de festas, bagunça e uso de drogas ilícitas. Dentro desse contexto, o vírus SARS-Cov2 chegou ao nosso país, tornando o cenário político brasileiro ainda mais caótico. Ministro da saúde pede demissão em plena pandemia e o Ministério da Educação encontra-se sem ministro. O conjunto de problemáticas têm afetado os profissionais da educação e pesquisa, sendo agravado com isolamento social. Além disso, a qualidade de vida passa a ser um "produto vendido" nas mídias sociais. Nos fragmentos em destaque observamos sentimentos de preocupação com o externo por parte do autor do texto.

Valores em comum: preocupação com externo, indignação com as ações da sociedade e com a qualidade de vida proposta nas mídias sociais.

Em alguns relatos foi possível identificar um sentimento relacionado com o externo. Neste sentimento aparece a indignação com o momento atual, no qual, muito se propõe nas mídias um padrão de vida, em que devemos nos manter calmos, praticando exercícios e com alimentação saudável. A preocupação com o externo aparece quando o professorpesquisador (enquanto cientista) precisa demonstrar um comportamento tido como "ideal", respeitando o isolamento social, seguindo as proposições do Ministério da Saúde. Posteriormente, esse sentimento é acompanhando de um sentimento de revolta em decorrência do argumento constituído por aqueles que não respeitam a quarentena e estão naturalizando a morte.

Carlos Marcos: É unânime a declaração que precisamos estar com a *mente calma*, com o *sono em dia*, *bem alimentados* $e$ *praticando exercícios*" (sentimento de indagação) "para a escrita fluir. Mente calma? Com esse desmonte na educação acontecendo numa grandiosidade nunca vista? Com cortes que faz a maioria destes leitores não terem bolsa de estudos? [...] E a pandemia que nos mostra um negacionismo de quem a gente nem imaginava? (L. $51-56)$.

Anne: [...] acho que a mudança ocasionada pela pandemia não foi muito positiva pra mim, sai de uma rotina onde eu trabalhava com mais afinco e determinação. (L. 21 - 23).

Esperança: [...] a aflição e angústia se tornam os principais sentimentos do dia a dia. A saudade de quem realmente amamos aperta e isso acaba por afetar nossa produção diária na pesquisa. (L. 69 - 71).

Violeta: [...] o distanciamento tem afetado meu rendimento e satisfação profissional, ainda não encontrei um ponto de equilíbrio, tenho me esforçado. (L. 187 - 188).

\section{Considerações Finais}

Ao realizarmos uma análise ancorada nos pressupostos do Círculo de Bakhtin já tínhamos consciência das dificuldades empreendidas. Contudo, o exercício de análise aqui efetivado e que trazemos neste artigo, nos propiciou um “olhar" diferenciado para o discurso enquanto elemento vivo e presente na sociedade e, na qual estão inscritos diferentes discursos partilhados e compartilhados no nosso contexto social e histórico. Após a leitura atenta dos relatos, destacamos que é 
possível assinalar enunciados em que não há somente concordâncias, mas que se instauram entre os sujeitos relações de afastamento, recusa, ansiedade e adaptação. Existem, nos relatos, um cotejo entre a realidade vivida e as funções do professorpesquisador em um momento único, distinto e inesperado, que o faz perceber sua profissão, assim como sua posição social, como distintas de outros campos da sociedade.

Foi possível perceber nos relatos (enunciados) equipolências de vozes que estabelecem entre si relações dialógicas. O enunciado é uma unidade discursiva e se constrói a partir do já dito ligando-se ao não-dito e aos enunciados que serão ainda ditos.

Podemos destacar algumas consequências não ditas em relação ao peso da profissão, como, a questão da autoformação em relação as competências digitais e as próprias preferências entre modalidades didáticas presenciais e uma certa "concepção" de desvalorização baseada na ênfase dos materiais didáticos e nas técnicas em relação aos docentes da modalidade de educação a distância presente no Brasil (Arruda \& Arruda, 2015), respigando tal concepção na modalidade remota e emergencial. Uma questão que está ainda em processo e que está sendo posto à prova, devido aos esforços de ajustes das secretarias de educação e instituições de ensino por um lado, e muitos alunos e professores se adaptando as melhores estratégias ao seu contexto, por outro. Esse cansaço pode ser devido à estruturas cristalizadas de trabalho para a construção de novas dinâmicas de trabalho docente. Em parte, por repetir ao que, tradicionalmente, se fazia nas escolas; por outra. em construir atividades diversificadas com as novas ferramentas e meios de comunicação em tão pouco tempo.

O que não está presente em referência a valorização da profissão docente e da ciência está na associação do docente com autoridade científica, hora em apresentar como conteúdo dogmático e emprega uma certa fé (em especial na confiança da vacina contra Covid-19), hora apresenta uma visão "sacerdotal" de dedicação profissional para além das condições materiais que, possivelmente, não o faria, mesmo na atividade presencial docente. Logo, a valorização está ligada as condições materiais, sociais e econômicas que associam a disponibilidade de produtos técnico-científicos que corroboram a confiança na própria ciência, em que o professor é identificado/associado. Isto, muitas vezes, está desassociada do contexto de produção da própria ciência e da formação do capital social para a construção dos artefatos científicos e técnicos, relacionados, por vezes, a uma forma mágica (esotérica), um oráculo, à solução dos problemas. Todavia, a ciência oferece caminhos sugeridos possíveis, construídos com o tempo e que nunca deixou de ser uma construção política e cultural na sociedade, e não um consumo acrítico. Assim, necessita de uma visão epistemológica balizada da realidade e não à mera venda de produtos científicos no mercado.

$\mathrm{Na}$ ideologia do otimismo ao momento vivenciado está em parte, um silêncio referente ao esforço empregado não remunerado, despesas não contabilizadas e, muitas vezes, relacionamentos desgastados em casa, ou com outros profissionais nas plataformas pela pressão, estresse e erros ocasionados pelo processo de aprendizagem. Não se nega a virtude da generosidade e nem potencialidade profissional manifestada em momentos de crise. Todavia, não se pode ter superação sem custo e nem tão pouco banalizar o sofrimento da frustração na inaptidão, da inabilidade e da incompetência quando os recursos e o treinamento são desfavoráveis ao desenvolvimento no tempo devido (não só as pressas).

A preocupação com o externo é evidenciada pela interação nas plataformas digitais, como afetar-se pelas interações em mídias que demonstram como ter qualidade de vida dentro do contexto pandêmico e usuários que mesmo com a circulação do vírus continuaram a interagir presencialmente com outras pessoas, tendo consciência do risco, pressão de grupos e opiniões diversas das crenças e convicções que tem estes professores. A sensação discursiva de nós contra eles. Ou eles atacam contra os nossos consensos. Evidenciando a necessidade de boas práticas republicanas e democráticas do diálogo aberto e respeitoso que, por vezes, é descartado para a voz autoritária (uso da autoridade do campo da saúde, da segurança pública, do comércio etc.) e da voz autoritarista (uso dogmático e opressor/monológico da opinião). O efeito valorativo enunciativo com os interlocutores nessa relação de dialogismo, mostra que as redes nem sempre são locais de diálogos, mas se apresentam como 
bolhas de opiniões e erosão da autoridade e do consenso científico com base em grupos de interesse e reprodução acrítica de ideologias (D’Ancona, 2018). Isso não quer dizer que os educadores e pesquisadores devem se calar e aceitar tal imposição, mas considerar que há situações e estruturas sob influência controlada que não aceita a apresentação racional da argumentação em arena pública.

É neste emaranhado que se instauram as percepções de professores-pesquisadores em um momento distinto, confuso, contraditório e controverso em que ideias de uma sociedade sobre o "ser professor" podem ser avaliadas e validadas, ou quiçá alteradas positivamente. Esta foi uma das ideologias constituídas por esse grupo que, em maior ou menor grau, fizeram-se presentes nos relatos analisados.

Assim o objetivo deste estudo foi conhecer as percepções e manifestações presentes nos discursos de professores em formação de pesquisa e de pesquisadores, em um momento especial da sua carreira (trabalho remoto e isolamento social). Neste sentido indicamos que outras pesquisas podem ser realizadas na perspectiva de compreender quais os reflexos deste momento na carreira do professor. O que muda na postura didática dos professores? Como se instaura o processo de retorno ao presencial? Estas e outras questões podem nos levar à indicadores de uma nova realidade para o ensino nas escolas e universidades.

\section{Referências}

Arruda, E. P., \& Arruda, D. E. P. (2015). Educação à distância no brasil: políticas públicas e democratização do acesso ao ensino superior. Educação em revista, 31(3), 321-338, Sept. doi: 10.1590/0102-4698117010

Bakhtin, M. (2003). Estética da criação verbal. Tradução de Paulo Bezerra. (4th ed.). Martins Fontes.

Bakhtin, M. (2016). Os gêneros do discurso. Tradução de Paulo Bezerra. Editora 34.

Bakhtin, M. (2017). Notas sobre literatura, cultura e ciências humanas. Tradução de Paulo Bezerra. Editora 34.

Bakhtin, M., \& Voloshinov, V. (1979). Marxismo e filosofia da linguagem. Tradução de Michel Lahud \& Yara Frateschi Vieira. Hucitec.

Brait, B. (2006). Uma perspectiva dialógica de teoria, método e análise. Gragoatá, 11(20), 47 - 62. https://periodicos.uff.br/gragoata/article/view/33238

Brait, B., \& Melo, R. (2017). Enunciado/enunciado concreto/enunciação. In: Brait, B. (Ed.). Bakhtin: conceitos-chave (pp. 61 - 78). Contexto.

D’Ancona, M. (2018). Pós-verdade: a nova guerra contra os fatos em tempos de Fake News. Faro Editorial.

Fiorin, J. L. (2016). Introdução ao pensamento de Bakhtin. Contexto.

Miotello, V. (2005). Ideologia. In: Brait, B. (Org.). Bakhtin: conceitos-chave (pp. 167 - 176). (2nd ed.). Contexto.

Pereira, A. S., Shitsuka, D. M.; Parreira, F. J., \& Shitsuka R. (2018). Metodologia da pesquisa científica. UFSM, https://repositorio.ufsm.br/bitstre am/handle/1/15824/Lic_Computacao_Metodologia-Pesquisa-Cientifica.pdf. 